\title{
Assessment and management of dry eye disease
}

\begin{abstract}
The topic of the 1984 Cambridge Ophthalmological Symposium was 'The Dry Eye'; it was chaired by my colleague and mentor Mr Peter Wright. In the 33 years that have passed since then we have learned a great deal more about this condition. This short paper sets out to review some of the more recent developments.
\end{abstract}

Eye (2018) 32, 200-203; doi:10.1038/eye.2017.289; published online 5 January 2018

\section{Definitions}

The term 'keratoconjunctivitis sicca' was coined by Henrik Sjögren in $1933^{1}$ and was subsequently applied to both Sjögren Syndrome and non-Sjögren Syndrome dry eye. In 1995, a working group from the National Eye Institute and Industry offered the following definition of what it termed dry eye disorder.

'Dry eye is a disorder of the tear film due to tear deficiency or excessive tear evaporation, which causes damage to the interpalpebral ocular surface and is associated with symptoms of discomfort'. ${ }^{2}$

A new definition was adopted by the Tear Vision and Eye Research Unit, Anglia Ruskin University, Cambridge, UK

\section{Correspondence:} RJ Buckley, Faculty of Medical Science, Vision and Eye Research Unit, Anglia Ruskin University, Health Building YST 213, East Road, Cambridge CB1 1PT, UK

Tel: +44 (0)8451962721

E-mail: Roger.Buckley@

anglia.ac.uk

Received: 17 October 2017 Accepted: 30 October 2017 Published online:

5 January 2018
Film and Ocular Surface Society's International Dry Eye Workshop in 2007, which is as follows.

'Dry eye is a multifactorial disease of the tears and ocular surface that results in symptoms of discomfort, visual disturbance, and tear film instability with potential damage to the ocular surface. It is accompanied by increased osmolarity of the tear film and inflammation of the ocular surface'. ${ }^{3}$

There were several innovations here: the multifactorial nature of the condition, a defining emphasis on increased tear osmolarity, and the first use of the term 'Dry Eye Disease' (DED).

After 2 years of work, the second International Dry Eye Workshop reported in the summer of 2017, having involved 12 subcommittees consisting of 150 experts from 23 countries. A new definition of DED was offered, which is as follows.

'Dry eye is a multifactorial disease of the ocular surface characterised by a loss of homoeostasis of the tear film, and accompanied by ocular symptoms, in which tear film instability and hyperosmolarity, ocular surface inflammation and damage, and neurosensory abnormalities have aetiological roles'. ${ }^{4}$

The new features of this DED definition include loss of homoeostasis, which is a useful concept clinically in that it may help to determine approaches to management, and neurosensory abnormalities, which underlines the disconnect between symptoms and signs that we so often see in our patients.

\section{Types of dry eye disease and its prevalence}

As is well known, there are two major categories of DED, aqueous-deficient (equating with reduced lacrimal gland function) and evaporative (equating very largely with meibomian gland dysfunction). Evaporative dry eye is far commoner than aqueous-deficient dry eye, and many patients have both forms concurrently. ${ }^{5}$

The tear film is important to vision as the first refracting surface of the eye. Its volume is around $7 \mu \mathrm{l}$ and it is produced at $1.7 \mu \mathrm{l} / \mathrm{min}$, with a $25 \%$ turnover per minute; however, these figures can only be illustrative as tear production is variable over a large range, being dependent on environmental and other conditions. For the purposes of tear film research, temperature, relative humidity, and airspeed can all be controlled in a controlled environment chamber. Other factors which affect tear production are more difficult to control, such as pain, bright light, stimulation of the nasal mucosa, and inputs from the higher centres, including emotional tearing.

The global prevalence of DED is not constant. It is highest in South East Asia, and lowest in Europe and the USA. Prevalence increases with 
age, with signs showing a greater increase per decade than symptoms. Women have a higher prevalence than men. Although most workers have found that tear parameters change with age, with volume, Schirmer score and break-up time reducing, and osmolarity increasing, $, 6,7$ others have found no significant age differences, except that osmolarity increases with age in females.

Tomlinson's group suggested that in DED there are pathological processes at work, particularly meibomian gland dysfunction, and that dry eye is hence an acquired disease rather than an age-related change. ${ }^{8}$

\section{Assessment of dry eye disease}

There are many programmes for the assessment of patients with DED, comprising the recording of symptoms and a variable number of observations and measurements, which might include tear secretion, tear clearance, ocular surface damage, tear film stability, tear volume, lipid layer assessment, and tear osmolarity. There are many ocular surface symptom questionnaires. The Ocular Surface Disease Index consists of 12 questions and is a much-used and validated instrument for measuring the subjective severity of DED. ${ }^{9}$

Ocular surface damage can be assessed with stains and by cytology, either by impression or with the aid of the confocal microscope. The Oxford Scheme is often used for grading ocular surface staining in steps from 0 to 5 , using fluorescein and rose bengal or lissamine green, as described by Bron et al in 2003. ${ }^{10}$ Tear film stability is an important part of the clinical assessment of dry eye disease. The non-invasive break-up time requires a special instrument, but the fluorescein break-up time can be easily measured at the slit lamp and should be carried out in every patient. A helpful adjunct to the slit lamp examination is an audible signal indicating seconds (eg, a mechanical or electronic metronome).

Ideally, some attempt, beyond recording the break-up time, should be made to assess the lipid layer of the tear film. Interferometry is not normally available in the clinic, and nor is meibometry, in which the quantity of meibomian oil on the lid margin is measured. Both of these are research tools, but meibography could be used routinely in the clinic. The everted lid is scanned with an infra-red light source and an image of the meibomian glands is immediately seen and can be photographed. Structural abnormalities are usually obvious and can be scored. ${ }^{11}$

In recent years, a consensus has been reached that tear osmolarity is the single best marker of dry eye disease severity. The most generally used clinical and research instrument is the TearLab Osmometer, which estimates osmolarity from the electrical impedance of a $50 \mathrm{nl}$ tear sample collected from the lateral meniscus. Many workers have suggested values or ranges for the osmolarity of normal tears. It is generally accepted that the threshold for mild to moderate dry eye disease is at $308 \mathrm{mOsm} / 1$. Many years ago it was proposed that tear osmolarity and plasma osmolality were related and more recently it was suggested that tear measurements could help in the diagnosis of systemic dehydration. ${ }^{12}$ We have demonstrated that the osmolarity of tears can be driven down to a basal level resembling that of plasma by $45 \mathrm{~min}$ of eye closure. ${ }^{13}$

Although osmolarity measurements correlate best with severity in DED, and the Schirmer test least well, ${ }^{14}$ this test, introduced as long ago as 1903, is cheap, quick, and universally available. The fact that it has been identified as the least satisfactory marker of DED severity is partly explained by the lack of consistency in its use: the type of strip, its position, whether the eyes are open or closed, whether a topical anaesthetic or no anaesthetic is used, and the evaporation of tear fluid from the strip during the 5 -min test, which varies with environmental conditions. However, for clinical purposes it remains a useful measure of tear production, so ways need to be found by which it can be improved. In a recent poster it was proposed that the Schirmer test can provide a reliable measure of actual tear production, provided at least three readings are taken, at 3,4 , and $5 \mathrm{~min} .{ }^{15}$ Evaporation during the course of the Schirmer test can be prevented by sheathing the strip in a pocket of impermeable plastic. Using a controlled environment chamber, we investigated this refinement at different relative humidities and we found that the wetting length was always significantly greater in sheathed strips. ${ }^{16}$

\section{Dry eye disease management}

The principles of DED management start with controlling the ocular environment, if possible. This means advising the patient to avoid dry atmospheres, high airspeeds including fans, car heaters and air conditioning, and being aware of the effects of concentration on blink rate. Concentration includes reading, working at the computer screen, and the use of digital devices. External protection of the ocular surface is quite difficult to achieve but is sometimes helpful, as are contact lenses in some cases, and here the choice is often between silicon hydrogel lenses with their low water content and scleral lenses which cover the entire exposed ocular surface. In aqueous deficiency DED, punctal plugs or cautery can be effective in conserving tears.

There is a huge literature on DED Management. Last year a Cochrane Systematic Review found that most overthe-counter artificial tear preparations are similarly effective. ${ }^{17}$ Some success has been achieved with antioxidants, and viscosity enhancers such as drops 
containing HPMC or hyaluronic acid are much used. Hypo-osmolar drops have been available for years and there is interest in newer osmoprotectants, including trehalose, a non-reducing sugar whose molecules cluster in aqueous solution.

Lipids combined with viscosity enhancers have been shown to be more effective than either alone. ${ }^{18}$ Treating the closed eye with a liposome-containing spray may at first seem a strange way to target the ocular surface, but the drug crosses the lid margins after a few blinks and then, with the ability of phospholipids to generate surface monolayers, thickens the lipid layer of the tears for 60-90 min. ${ }^{19}$ Autologous serum, prepared from the patient's own blood, is very similar to natural tears, being of the correct $\mathrm{pH}$ and containing nutrients, vitamins,

fibronectin, epithelial, and nerve growth factors, but there are legal hurdles involved in its preparation and it is very expensive, a single batch costing $£ 1300$ in $2008 .{ }^{20} \mathrm{~A}$ recently published multi-centre European RCT of ciclosporin $0.1 \%$ emulsion showed improvement of symptoms and signs in patients with moderate to severe DED. ${ }^{21}$ Steroids have been used for many years in DED where there is significant inflammation, and the usual caveats of steroid usage apply: short periods of use and the 'less-penetrating' drugs are to be preferred. There is a host of newer drugs at various stages of development including clinical trials. One that was licensed by the FDA last year was Lifitegrast, an integrin inhibitor that downregulates T-lymphocyte-mediated inflammation. ${ }^{22}$

Lid hygiene remains one of the mainstays of the management of meibomian gland dysfunction, and there is still little evidence that commercial alternatives are superior to diluted baby shampoo. Warm compresses are soothing and may liquefy solidified meibomian secretions. Intense pulsed light therapy has received much publicity of late but so far only one RCT has been published. We in this country have been using systemic tetracyclines for years but a 2016 report for the American Academy of Ophthalmology revealed that of eight studies only one was a RCT. ${ }^{23}$ Although all these studies documented an improvement in meibomian gland dysfunction, albeit commonly associated with side-effects, no level 1 evidence was found to support the use of oral antibiotics in the management of ocular surface disease. Topical macrolides, specifically azithromycin, show promise, as was illustrated for example in the 2016 study of Hosseini. ${ }^{24}$

Diet and dietary supplements are two different things. As an association between low dietary intake of omega-3 essential fatty acids and DED has been shown, ${ }^{25}$ it makes sense to advise a diet rich in these EFAs in Dry Eye patients. However, we have few high-quality RCTs to enable us to assess the value of omega- 3 and omega- 6 supplements in these patients. A meta-analysis of seven studies involving 790 participants showed that omega-3 supplementation improved break-up times and Schirmer scores, but had no significant effect on symptoms. ${ }^{26}$

\section{Conclusion}

Our understanding of DED has advanced very considerably since 1984, when the topic was last considered in depth at the Cambridge Ophthalmological Symposium. This has led to improvements in detection and management of this common condition, which have benefited our patients.

\section{Conflict of interest}

The author declares no conflict of interest.

\section{References}

1 Sjögren H. Zur Kenntnis der keratoconjunctivitis sicca. Acta Ophtalmol 1933; 11(Suppl. II): 1-151.

2 Lemp MA. Report of the National Eye Institute/Industry Workshop on Clinical Trials in Dry Eyes. CLAO J 1995; 21(4): 221-232.

3 Lemp MA, Baudouin C, Baum J, Dogru M, Foulks GN, Kinoshita $S$ et al. The definition and classification of dry eye disease: report of the definition and classification Subcommittee of the International Dry Eye Workshop. Ocul Surf 2007; 5 (2):75-92.

4 J. Daniel Nelson JD, Craig JP, Akpek EK, Azar DT, Belmonte C, Bron AJ et al. TFOS DEWS II introduction. Ocul Surf 2017; 15: 269-275.

5 Lemp MA, Crews LA, Bron AJ, Foulks GN, Sullivan BD. Distribution of aqueous-deficient and evaporative dry eye in a clinic-based patient cohort: a retrospective study. Cornea 2012; 31: 472-478.

6 Mathers WD, Lane JA, Zimmerman MB. Tear film changes associated with normal aging. Cornea 1996; 15(3): 229-234.

7 Ozdemir M, Temizdemir H. Age- and gender-related tear function changes in normal population. Eye 2010; 24: 79-83.

8 Craig JP, Tomlinson A. Age and gender effects on the normal tear film. Adv Exp Med Biol 1998; 438: 411-415.

9 Schiffman RM, Christianson MD, Jacobsen G, Hirsch JD, Reis BL. Reliability and validity of the ocular surface disease index. Arch Ophthalmol 2000; 118(5): 615-621.

10 Bron AJ, Evans VE, Smith JA. Grading of corneal and conjunctival staining in the context of other dry eye tests. Cornea 2003; 22(7): 640-650.

11 Arita R, Itoh K, Inoue K, Amano S. Noncontact infrared meibography to document age-related changes of the meibomian glands in a normal population. Ophthalmology 2008; 115(5): 911-915.

12 Fortes MB, Diment BC, Di Felice U, Gunn AE, Kendall JL, Esmaeelpour $\mathrm{M}$ et al. Tear fluid osmolarity as a potential marker of hydration status. Med Sci Sports Exerc 2011; 43(8): 1590-1597.

13 Willshire C, Buckley RJ, Bron AJ. Estimating basal tear osmolarity in normal and dry eye subjects. Cont Lens Anterior Eye 2017; epub ahead of print 22 September 2017; doi: 10.1016/j.clae.2017.09.005. 
14 Sullivan BD, Whitmer D, Nichols KK, Tomlinson A, Foulks GN, Geerling G et al. An objective approach to dry eye disease severity. Inv Ophthalmol Vis Sci 2010; 51(12): 6125-6130.

15 Radke CJ, Kim YH, Li W, Lin MC. Schirmer strips provide reliable tear-production rates. Inv Ophthalmol Vis Sci 2017; 58 (8): 478.

16 Willshire C, Buckley RJ, Bron AJ. Standardising the Schirmer test by enclosing the strip in a waterproof sheath. Acta Ophthalmol 2015; 93(S255).

17 Pucker AD, Ng SM, Nichols JJ. Over the counter (OTC) artificial tear drops for dry eye syndrome. Cochrane Database Syst Rev 2016; (Issue 2): CD009729.

18 Tomlinson A, Madden LC, Simmons PA. Effectiveness of dry eye therapy under conditions of environmental stress. Curr Eye Res 2013; 38(2): 229-236.

19 Craig JP, Purslow C, Murphy PJ, Wolffsohn JSW. Effect of a liposomal spray on the pre-ocular tear film. Cont Lens Anterior Eye 2010; 33(2): 83-87.

20 MacLennan S, Hartwig D, Geerling G. Experiences with a centralised national service for autologous serum eyedrops in England. Ophthalmologe 2008; 105(7): 639-643.

21 Baudouin C, Figueiredo FC, Massmer EM, Ismail D, Amrane M, Garrigue JS et al. A randomised study of the efficacy and safety of $0.1 \%$ cyclosporine A cationic emulsion in treatment of moderate to severe dry eye. Eur J Ophthalmol 2017; 27(5): 520-530.

22 Godin MR, Gupta PL. Lifitegrast ophthalmic solution in the treatment of signs and symptoms of dry eye disease: design, development, and place in therapy. Clin Ophthalmol 2017; 11: 951-957.

23 Wladis EJ, Bradley EA, Bilyk JR, Yen MT, Mawn LA. Oral antibiotics for meibomian gland-related ocular surface disease: a report by the American Academy of Ophthalmology. Ophthalmology 2016; 123(3): 492-496.

24 Hosseini K, Lindstrom RL, Foulks G, Nichols KK. A randomized, double-masked, parallel-group, comparative study to evaluate the clinical efficacy and safety of $1 \%$ azithromycin- $0.1 \%$ dexamethasone combination compared to $1 \%$ azithromycin alone, $0.1 \%$ dexamethasone alone, and vehicle in the treatment of subjects with blepharitis. Clin Ophthalmol 2016; 10: 1495-1503.

25 Miljanovic B, Trivedi KA, Dana MR, Gilbard JP, Buring JE, Schaumberg DA. Relation between dietary n-3 and n- 6 fatty acids and clinically diagnosed dry eye syndrome in women. Am J Clin Nutr 2005; 82(4): 887-893.

26 Liu A, Ji J. Omega-3 essential fatty acids therapy for dry eye syndrome: a meta-analysis of randomized controlled studies. Med Sci Monit 2014; 20: 1583-1589. 